\title{
Legal Doctrine As a Non-Normative Discipline
}

\section{A Refinement of Niiniluoto's and Aarnio's Distinction between Norm-Descriptions, Norm-Contentions and Norm-Recommendations ${ }^{*}$}

\author{
Anne Ruth Mackor
}

\section{Introduction}

\subsection{The problem}

Many legal theorists claim that legal doctrine is a normative discipline. They argue that the aim of legal scholars is not only, or not even primarily, to describe law, but rather to evaluate it. Moreover, the aim of legal scholars is to persuade legal officials to accept and, if possible, to apply their evaluative views and to adjust law accordingly. In this paper I will argue against this claim. The most pressing reason why we should bother about this subject is that evaluative, prescriptive and persuasive statements are thought to be subjective, or at least less objective than descriptive statements. If legal doctrine is normative, it is unscientific, or at least less scientific than other sciences, or so it is argued.

There are at least two viable routes to rebut the accusation that legal doctrine is less of a science than other disciplines. One way is to show that normative statements are not subjective in any worrying sense and that a normative science can be truly objective and scientific. One such argument is, in short, to agree with the critique that prescriptive and evaluative statements cannot be true or false in a correspondence theoretical sense and that they are in that respect unlike descriptive empirical statements. ${ }^{1}$ However, if they are based on a well-articulated theory, they can be justified and criticised by means of some of the methods by which we assess descriptive empirical statements, among others by means of criteria of clarity, precision and coherence with other statements. In that sense, they are objective or at least intersubjective. ${ }^{2}$

The other route to rebut the accusation that legal doctrine is less scientific than other scientific disciplines is to argue that legal doctrine is not normative, at least

* I thank Jaap Hage, Pauline Westerman and two anonymous referees for their comments on an earlier version of this paper. I thank Ed Zalta for answering my questions about the abstract object theory. Remaining misunderstandings of his theory and possible misapplications to law are my own responsibility.

1 They cannot be true or false since they do not have a word-to-world direction of fit. Prescriptive statements have a world-to-word direction of fit and evaluative statements do not have a direction of fit even though they presuppose a word-to-world direction of fit. See Searle 1983 on the idea of a direction of fit. Also see section 3.3. See section 2.2 on the correspondence theory of truth.

2 There is no room to elaborate on the notion of objectivity. For an overview see e.g. Leiter 2002 and Stavropoulos 2006. Also see Niiniluoto 2008. 
not more normative than other scientific disciplines. In this paper I discuss and defend this route. ${ }^{3}$ I argue that one aim of legal doctrine is to offer a description of the positive legal order under investigation and that the second aim is to offer a rational reconstruction of that order. This view of legal doctrine is not new. ${ }^{4}$ What is distinctive of my approach is that I make use of the abstract object theory to defend the view that these rational reconstructive statements are descriptive in nature. In section 3 I offer a sketch ${ }^{5}$ of the abstract object theory and of the way in which it might help to resolve the quarrel about the nature of legal doctrine.

In the remainder of section 1 I first expound the standard view of legal doctrine. Subsequently I introduce and discuss Niiniluoto's and Aarnio's distinction between norm-descriptions, norm-contentions and norm-recommendations. This distinction plays a pivotal role in my analysis of the nature of legal doctrine. Section 2 and 3 are the core of this paper. In section 2 I compare legal doctrinal descriptions with social scientific descriptions and argue that large parts of legal doctrinal descriptions of law are similar to social scientific descriptions of law. ${ }^{6}$ For that reason I call them empirical norm-descriptions. Section 3 is devoted to non-empirical norm-descriptions. In section 3 I introduce and discuss the distinction between concrete and abstract objects. It plays a foundational role in my argument that a large part of legal doctrine consists of non-empirical statements that are truly descriptive in nature. In section $4 \mathrm{I}$ briefly deal with norm-contentions and norm-recommendations. In section 5 I summarize my argument and conclude that the larger part of legal doctrine is a non-normative, descriptive, enterprise.

\subsection{The standard view of legal doctrine and a critique}

The standard view of legal doctrine consists in the claim that legal doctrine offers some descriptive statements about the validity and the content of legal norms of particular positive legal orders. ${ }^{7}$ Large part of legal doctrine, however, is claimed to consist of evaluative statements, sometimes about the validity, but mostly about the content of legal norms. These evaluative statements belong to the 'core

3 Many other worries about the scientific character of legal doctrine, such as the worry that one cannot speak of progress in legal doctrine and the worry that legal doctrine offers no explanatory theories, will not be tackled in this paper. See Mackor 2011, p. 48-58 on the explanatory nature of legal doctrine.

4 MacCormick's and Summers' 1991 concept of rational reconstruction of an institutional normative order is closely related to my view. However, they do not analyze the nature of rational reconstructive statements or the implications for the nature of legal doctrine. Moreover, MacCormick 2007, p. 291 seems to defend the view that rational reconstructions are normative. My view is perhaps most akin to Brouwer 1999. I discuss Brouwer's analysis in sections 2.2 and 3.4.

5 To my knowledge the abstract object theory has not been applied to law. A more in-depth analysis could combine the abstract object theory with the institutional theory of law of e.g. MacCormick \& Weinberger 1986 and MacCormick 2007 or Ruiter 1997 and 2001. I believe this combination is more fruitful than the combination of the institutional theory of law with Popper's theory of three worlds that e.g. MacCormick 2007 proposes.

6 They are not identical however. See section 3, especially 3.6.

7 See Mazzarese 1991 for the claim that legal doctrine cannot offer any descriptive statements, because all descriptions are interpretations and interpretation is evaluative. See Niiniluoto 1991 for a rebuttal. Also see section 2.3. 
business' of legal doctrine, in particular because they are part of the answer to the question how vagueness, ambiguities, gaps and injustices in the positive legal order could or should be dealt with. These evaluations can result in prescriptive or at least persuasive statements, addressed to legal officials, to change the law, i.e. the validity or the content of a norm, accordingly.

Before I can tackle the standard view, I need to introduce some terminology. I follow Niiniluoto (1985, p. 184-188) and Aarnio (1987, p. 51-53) in calling empirical and logical statements about legal norms norm-descriptions, in calling evaluative statements norm-contentions and in calling persuasive statements norm-recommendations. Norm-descriptions are statements like ' $\mathrm{N}_{1}$ is a valid norm of Dutch law' and 'The content of $n_{1}$ is $c_{1}$ '. Norm-contentions are statements like 'It is good that $\mathrm{n}_{1}$ is a valid norm of Dutch law', 'It is good that $c_{1}$ is the content of norm $n_{1}$ ' or 'It would be best if $c_{2}$ were the content of norm $n_{1}$ '. Norm-recommendations, finally, are statements like ' $\mathrm{N}_{2}$ should be a valid norm of Dutch law' and ' $C_{2}$ should be the content of $\mathrm{n}_{1}$ '.

I believe, however, that the threefold distinction between descriptions, contentions and recommendations is too simple for our purpose, viz to analyze the nature of legal doctrine. We need to make a distinction between two kinds of statements that Niiniluoto and Aarnio do not distinguish and that they would probably both call norm-contentions. ${ }^{8}$ If we do so it becomes clear that whereas one type of norm-contention is definitely evaluative, the other is not evaluative or at best evaluative in a very different sense of that term. The truly evaluative normcontentions assess (part of) the legal system in terms of extra-legal, e.g. moral, political, religious or economic criteria. Neither legal scholars nor legal officials need to share these criteria; they can be the strictly personal choice of the particular legal scholar. Also, these extra-legal criteria might form a coherent theory, but they need not. I agree with Niiniluoto and Aarnio that these norm-contentions are evaluative statements and that they are therefore rightly called norm-contentions. $^{9}$

Next to this truly evaluative type of norm-contentions there is another type of statements that many if not most legal scholars and legal theorists would also call evaluative. The central claim of my paper is that these statements are normdescriptions. They are like norm-contentions in that these statements too allow the legal scholar to critically evaluate norms of the positive legal order under investigation. The difference, however, is that this evaluation takes place on the basis of criteria:

1. that are intra-legal, i.e. are part of the positive legal order under investigation;

2. that legal scholars need not accept, but that most legal officials of the positive legal order, as officials of that specific legal order, i.e. not necessarily as pri-

8 If Niiniluoto and Aarnio agree with me that these statements are norm-descriptions, my exposition can be read, not as a critique, but as a more in-depth analysis of their notion of normdescriptions.

9 Niiniluoto and Aarnio do not claim that these contentions are subjective, however. Although these statements do not correspond to states of affairs in the world like empirical descriptions, they are subjective only if they are not supported by arguments. Aarnio 1987, p. 51 calls evaluations which are not supported by arguments pure expressions. 
vate persons, accept as valid criteria, or at least that they will accept if legal scholars explicitly present these criteria to them;

3. that acknowledge the largest and especially the most fundamental part of positive legal order as valid law;

4. that are fairly specific and hang together as a more or less coherent whole and thus could be formulated as a theory.

On the one hand, the legal doctrinal statements that are based on these criteria do not aim to offer a description of the positive legal order as it exists in the social world; on the other hand they do not aim to offer an evaluation or critique from the outside. Although these statements might be called evaluative, they differ from the extra-legal type of evaluations. They are much more akin to scientific, mathematical and logical statements that are intended to lay bare the, often unexpected, intra-theoretical implications of the scientific theory under scrutiny. Analogously, when legal scholars offer an interpretation of a particular norm, they will often point at the (unexpected) implications of their interpretation, viz that it is more coherent with the system of the positive legal order and better fits e.g. the literal meaning or the parliamentary history of the norm than other interpretations.

The aim of this paper is to further unravel the nature of this type of statements. I argue that the fact that the statements are based on criteria that belong to the positive legal order itself allows us to call them descriptions. They are descriptive because the claim that the criteria are part of the legal order can be empirically tested. Accordingly, the claim that a particular norm of this legal order fits or fails to meet these criteria can, in principle, be empirically ascertained too. However, since legal officials themselves have not (yet) declared that (the interpretation of) the norm as described by legal scholars is valid, the norm-description is not a description of a norm of the positive legal order as it exists in the social world. ${ }^{10}$ For that reason I call these statements non-empirical norm-descriptions.

An important implication of the foregoing is that legal scholars can only formulate this type of legal doctrinal non-empirical norm-descriptions about legal orders that in fact have a set of fairly specific and coherent intra-legal criteria. These criteria most likely exist in a community in which:

1. Law and morality are separated. When I say law and morality are separated, I do not mean to deny that substantive values and principles play an important role in the legal order. On the contrary, in some societies substantive moral values and principles have become an integral part of the positive legal order, in particular via the constitution and international treaties that make explicit reference to these values and principles as legal values and principles. Thus:

2. The positive legal order can contain substantive legal values and principles. The most important feature of legal orders that have such a set of fairly specific and coherent intra-legal criteria, however, is that: 
3. Law-creating powers are created and restricted by the legal order itself and largely laid down in explicit rules. This is the case in a constitutional state or 'rechtsstaat'.

In conclusion: non-empirical norm-descriptions can only be offered of positive legal orders that fulfil these three demands in such a manner that they have a set of fairly specific and coherent intra-legal criteria. I shall not argue for, but simply assume that at least some western legal orders, such as the legal order of the Netherlands, fulfil these demands. ${ }^{11}$

\subsection{Law as a social object, law as an abstract object}

In this paper I elaborate the claim that legal doctrine is a discipline that primarily offers norm-descriptions. On the one hand it deals with law as a social object and offers empirical descriptions of norms that are valid norms of a positive legal order that exists in the social world. On the other hand legal doctrine treats law as an abstract object and offers a non-empirical descriptive rational reconstruction of the positive legal order by means of intra-legal criteria. On top of this legal doctrine is also a normative discipline, since legal scholars sometimes evaluate law in the light of extra-legal criteria and offer recommendations (persuasions) to legal officials to change the law accordingly.

I will argue that the kernel of legal doctrine consists of empirical and non-empirical descriptive statements, whereas the third, normative, part is - or at least should be ${ }^{12}$ - only a sideline activity. In general, norm-contentions and normrecommendations, like the evaluative and persuasive remarks social scientists might add to their papers, should at most play a role in an obiter dictum to the 'truly scientific' part of their investigations. In fact, if the obiter dictum becomes the main part, the investigation is no longer legal doctrinal, but instead philosophical or political in nature.

In this paper I argue that we should distinguish between:

\section{Empirical norm-descriptions}

Empirical norm-descriptions explicate which norms are valid within the positive legal order under investigation or they explicate the content of the norms of that legal order. For example, the legal doctrinal statement that it is a valid norm of the Dutch Termination of Life on Request and Assisted Suicide (Review Procedures) Bill that cases of euthanasia carried out by doctors are to be judged by regional euthanasia review committees is a true empirical norm-description since

11 Positive legal orders fulfil these demands only to a certain extent. The criteria will not always be sufficiently specific to allow for a rational reconstruction with respect to all norms or even with respect to all domains of the positive legal order under scrutiny. Moreover complex western legal orders are making more use of so-called open norms that are to be 'filled in' by 'soft law', i.e. by rules that are made by persons who are not legal officials. As a consequence, not only the content of legal rules becomes much more indeterminate, but so does the answer to the question who is legally authorized to fill in the content of the open norms, i.e. when a norm is a legally valid norm. 
article 3 of this Bill authorizes committees and the committees in fact use their power to do so.

\section{Non-empirical norm-descriptions}

\section{A Logical norm-descriptions}

Logical norm-descriptions formulate the logical entailments of empirical normdescriptions.

Empirical norm-descriptions state what the literal content of legal norms is; nonempirical logical norm-descriptions take into account what straightforwardly follows from the content of the norm. For this reason we can say that the legal doctrinal statement that it is a valid norm of the Dutch Termination of Life on Request and Assisted Suicide (Review Procedures) Bill that cases of euthanasia carried out by nurses are to be judged by regional euthanasia review committees is a false norm-description since these committees are authorized to judge euthanasia only when it is carried out by medical doctors. ${ }^{13}$ Legal doctrine can make this claim even before one of the committees has ever received a reporting of a nurse. In the same manner legal scholars could say, again before there has been a concrete case, that it is a true norm-description that these committees are authorized to judge euthanasia carried out on psychiatric patients. ${ }^{14}$

Obviously, as soon as one or more committees nevertheless consider themselves authorized to judge a case of euthanasia carried out by a nurse or when they consider themselves unauthorized to consider a case of euthanasia with respect to a mentally competent person with a psychiatric disorder, positive law changes and so does the truth value of legal doctrinal norm-descriptions of this part of law. The first contra legem decision of a committee will probably result in an empirical norm-description stating that the content of the law is ambiguous on this point. However, when committees would stick to their new interpretation without being overruled by the legislator, positive law changes and the truth of both empirical and logical norm-descriptions will change accordingly.

\section{B Semi-logical and semi-fictional norm-descriptions}

Norm-descriptions that are both semi-logical and semi-fictional ${ }^{15}$ state which norms should be valid in the positive legal order under investigation or they state what the content of these norms should be. They do so by reference to the fairly specific and coherent set of intra-legal criteria that allows for a rational reconstruction of the positive legal order as an optimal internally coherent normative system.

13 In such a case, the coroner should not send the report by the nurse to the committee, but to the public prosecutor.

14 In 2008 there have been, for the first time since the Act came into force in 2002, two reports of euthanasia carried out on a psychiatric patient. See the Annual Report (in Dutch, 2008, p. 11-15) at <www.euthanasiecommissie.nl/Images/jaarverslag\%20RTE\%202008_definitief_tcm17-9036. pdf $>$.

15 In section 3.5 I explicate the meaning of 'semi-logical' and 'semi-fictional'. 
So in the example just offered, after the first contra legem decision of a regional euthanasia review committee legal scholars could not only offer the empirical norm-description that the law has become ambiguous on this point, but they could also offer the non-empirical norm-description that the decision of the committee conflicts with the text of the law, the parliamentary history, et cetera and that therefore, when looked at from an intra-legal rational reconstructive perspective, the decision does not fit positive law.

In the remainder of this paper I ignore logical norm-descriptions. Whenever I use the term 'non-empirical norm-descriptions' I refer to the semi-logical and semifictional norm-descriptions, viz the ones that are used in the rational reconstruction of law.

\section{Norm-contentions}

Norm-contentions are evaluative statements. They state which norms should be valid in the positive legal order under investigation or they state what the content of these norms should be. The assessment can be based on extra-legal criteria. These criteria can but need not form a coherent whole and they can but need not be shared by some legal officials in the community.

For example, a legal scholar who argues against the validity of the Dutch Termination of Life on Request and Assisted Suicide (Review Procedures) Bill on the ground that it does not respect the sanctity of life would thereby offer a normcontention since respect for the sanctity of life is not a principle recognised by Dutch law. ${ }^{16}$

\section{Norm-recommendations}

Legal scholars can try to persuade legal officials to take the same view on law and to change the law accordingly. There are two types of recommendations. I shall call them intra-legal and extra-legal recommendations respectively.

\section{A Intra-legal norm-recommendations}

Intra-legal norm-recommendations are offered on the basis of non-empirical norm-descriptions. Earlier I claimed that norm-contentions and norm-recommendations should only be side-line activities of legal scholars. I have to refine this claim. Intra-legal norm-recommendations follow from non-empirical normdescriptions and therefore belong to the core-business of legal doctrine in the same manner in which theoretical and methodological recommendations of empirical scientists belong to the core-business of the empirical sciences.

\section{B Extra-legal norm-recommendations}

Extra-legal norm-recommendations are offered on the basis of norm-contentions and therefore they (should) belong to the side-line activities of legal scholars.

In the remainder of this paper I will discuss the nature of empirical norm-descriptions (section 2) and non-empirical norm-descriptions (section 3) in great depth. 
I will only briefly discuss norm-contentions and norm-recommendations (section 4). I conclude that the main part of legal doctrine consists of empirical and non-empirical norm-descriptions and that it is therefore descriptive in nature (section 5).

\section{Empirical norm-descriptions}

\subsection{Law in books and law in action}

Empirical norm-descriptions are descriptive statements about the validity or the content of legal norms of a specific positive legal order, e.g. the Dutch legal order. 'Norm $\mathrm{n}_{1}$ is a valid norm of the Dutch legal order' is an empirical norm-description about the validity of norm $n_{1}$; 'The content of valid Dutch legal norm $n_{1}$ is $c_{1}$ ' is an empirical norm-description of the content of that norm. Niiniluoto points out that some of these norm-descriptions will consist of no more than a disjunction, i.e. a finite number of different interpretations, and some will only offer a partial characterization of the norm (1991, p. 370). ${ }^{17}$

Although many readers will agree with me that these norm-descriptions truly are descriptions of positive law, they will probably object to my claim that these descriptions are empirical. They will argue that I mix up legal-doctrinal descriptions of 'law in books' and sociological descriptions of 'law in action'. In this section I rebut this objection. First note that my claim is that empirical normdescriptions are empirical because they describe, or at least aim to describe, positive law, i.e. law that in some sense 'exists' in the social world. When I say that legal scholars aim to describe law as an object in the social world or as a social object I do not say that they aim to describe law in action, i.e. 'effective' law as it shows from the behaviour of the norm-addressees. Legal scholars focus on law in books, i.e. on valid rules that can be found in the writings of legal officials; they largely ignore law in action. Nevertheless, the question what law in books is, is an empirical question. Just as knowledge about law in action is achieved by studying the behaviour of norm-addressees in the social world, knowledge of law in books is acquired by studying the linguistic behaviour of legal officials that also exists in the social world.

In section 3.2 I say more about the way law 'exists' in the social world. First, however, I turn to the most important argument for my claim that empirical norm-descriptions really are empirical statements about law, namely that they can be said to be true or false in the 'normal', i.e. correspondence theoretical meaning of these words. When I want to know whether norm $n_{1}$ is an effective norm of positive legal order L, I have to observe the behaviour of norm subjects; when I want to know whether norm $n_{1}$ is a valid norm of positive legal order L, I have to observe the writings of legal officials. Readers will probably rebut that legal scholars do not observe, but rather interpret the text in law books. This is true, but it is not an objection to the analogy since the study of law in action is

17 In section 3.4 I argue that the same holds for non-empirical norm-descriptions. They too can often only offer a disjunctive or partial characterisation. 
just as much a matter of interpretation as the study of law in books. In section 2.3 I say more about the intricate nature of legal doctrinal and social-scientific interpretation; here my claim merely is that legal doctrinal descriptions of law in books are empirical norm-descriptions to the extent that the truth of an empirical norm-description is a matter of correspondence between the legal doctrinal statement and states of affairs in the social world. Since many legal scholars and philosophers misunderstand the correspondence theory of truth, I must first explicate the correspondence-theoretical nature of the truth of legal doctrinal empirical norm-descriptions before I can turn to the notion of interpretation in section 2.3.

\subsection{The correspondence theory of truth}

There are at least two seemingly ineradicable misunderstandings about truth. The most fundamental misunderstanding consists in the mixing-up of the meaning of the word "truth" with the way in which we can know and justify that a statement is true. The meaning of "The sentence 'Mackor is at home at this moment' is true" is that the sentence corresponds to a state of affairs in the world. However, the correspondence theory is not intended to answer the question how we know and justify that this sentence is true, i.e. that this correspondence obtains. In order to answer that question one has to make empirical inquiries and check on incoherencies between the statements that are made about the state of affairs under investigation.

The second misunderstanding about truth concerns the confusion of truth-conditions of sentences with their truth-values. Whereas the truth-conditions of empirical norm-descriptions are a matter of consensus among legal scholars, their truthvalues depend on the question whether the content of the norm-descriptions corresponds to the content of the norms of the positive legal order. Obviously, legal scholars can legitimately contest both the truth-conditions as well as the truthvalue of particular norm-descriptions. However, as long as the content and the truth-conditions are sufficiently specific and the norm-description is about a norm of law in books, the truth-value of norm-descriptions is not a matter of consensus between legal scholars, but of correspondence between the statement about the norm and the norm in the social world. ${ }^{18}$

Peczenik (2005, p. 5) has argued that the test of descriptive theories about law is not in their correspondence, but in their coherence with the words of the statute and with factual judicial practice. His claim, however, is based on a mistaken mixing of object-level (law) and theoretical level (legal doctrine). As with all descriptive theories, the aim of the descriptive part of legal doctrine is to achieve correspondence of the content of the statements of the legal doctrinal theory (theoretical level) with the content of the norms as they are formulated in statutes and as they show in the products of legal officials in the social world (object level). The test as to whether this correspondence is achieved obviously cannot be found in correspondence between the theory and the world. Knowledge of the relation has to be gained from the coherence of the statements. However this 
coherence is neither to be found on the object-level of law as a social object, nor between the object level and legal doctrinal level, but on the level of the legal doctrinal theory, i.e. in the coherence of the particular norm-description with other legal doctrinal descriptions. ${ }^{19}$

Brouwer's analysis of legal doctrine (1999, p. 224) can further illuminate the nature of the empirical part of legal doctrine. Brouwer calls legal doctrinal empirical theories equivalent systematizations of law. The term 'equivalent' points to the fact that the systematization should be equivalent to, i.e. correspond to, positive law. ${ }^{20}$ A first demand of such a systematisation is completeness; the description should cover all of (the part of) the positive legal order under investigation. This does not imply that law itself must be complete. Obviously, a description of law can be complete by describing incompleteness in the law itself. A second demand is clarity and precision; the descriptions should be as clear and as precise as possible. This does not imply, again, that lack of clarity or imprecision in the law itself is eliminated. On the contrary, in such a case the clarity and precision of the legal doctrinal description should consist, precisely, in making clear and precise where the law is inconsistent, vague or incomplete. The third demand, finally, is that the systematization should be frugal. This demand should be understood as secondary to the first two demands, since the frugality of the description should respect the completeness, the clarity and the precision of the systematization.

\subsection{Law as a social object ${ }^{21}$}

Some readers might object that even if the legal doctrinal study of law in books is just as empirical as the social scientific study of law in action since both aim at establishing statements that correspond to states of affairs in the world, the fact that legal doctrine studies law as a social object already implies that legal doctrine is normative since legal interpretation is inherently normative. ${ }^{22}$

Before tackling this issue, let us begin with the observation that all scientists agree, at least since the defeat of logical positivism, that scientific observations are steered by the scientific theory about the object under investigation and about the methods scientists use. For example, both the statement that this gas expands and the statement that all gases expand when heated are 'laden' by a theory about what gases are, what expansion is, etc. Just as importantly, both statements are also 'laden' by a theory about how one can reliably measure the rise of temperature and the expansion of gases.

Theory-ladenness results in normative claims. Theory-ladenness results, for example, in prescriptive claims about how scientists should measure temperature and when they ought to conclude that temperature has risen $\mathrm{x}$ degrees. Theory-laden-

20 This does not imply that the norm-description is linguistically identical to the norm itself. An identical formulation is only informative if there is a lack of clarity about the precise formulation, for example because the source is not available.

21 This section is an adapted version of Mackor 2011, Section IV.B, p. 60-62.

22 Smith 2009, for example, claims that even the most neutral or objective study of positive law presupposes a normative point of view. Soeteman 2009 argues that legal answers, in easy cases as well as in hard cases, always presuppose a normative interpretation of the legal sources. 
ness also results in evaluative claims, among others about the quality and reliability of the measurement and therewith about the quality of the scientific conclusions. Again note that these normative statements, which belong to the corebusiness of science, are not normative in a political, moral or religious sense.

As was explicated in section 2.2, theory-ladenness implies that the truth conditions of scientific statements are created through consensus among scientists. In other words, all sciences have a consensual basis. To offer a worn-out example, before it was finally decided that whales are mammals, scientists had to discuss what characteristics determine whether an animal is a fish or a mammal. In other words, they had to decide whether the fact that whales live in the water and have fins should determine that they are fish, or whether the fact that they have lungs and are viviparous should determine that they are mammals. ${ }^{23}$ Similarly, legal doctrinal empirical norm-descriptions are theory-laden. They presuppose a legal doctrinal theory that describes the sources of law and the accepted (hierarchy of) standards of interpretation and argumentation of the positive legal order under investigation. When there is no consensus among legal scholars about the sources of law and the standards of interpretation and argumentation, it is impossible to offer any legal doctrinal empirical norm-description.

However, these consensual, prescriptive and evaluative aspects of empirical sciences do not stand in the way of the truth value of the statement 'this concrete animal here and now is a mammal' being a matter of correspondence of the statement with reality. ${ }^{24}$ After scientists have decided upon the criteria for being a mammal, it is 'up to nature' so to speak to say whether a specific statement is true or false. This is important since truth in the sense of correspondence is often argued to be an important precondition for the objectivity of scientific statements.

Legal doctrine and the social sciences, however, have to deal with the additional problem that the facts they study are doubly theory-laden. In the first place, social scientific facts are not only laden with the theories of scientists, but also with the 'theories', i.e. worldviews of members of the community through which the social facts that scientists study come into existence in the first place. ${ }^{25}$ Second, these social facts are not merely laden with the descriptive 'theories' of the members of the community that social scientists study, but also with their normative, i.e. moral, political and religious evaluative and prescriptive 'theories'.

For example, a social scientist who studies changes in the number of physically violent acts in a particular community over the last ten years. He must not only take the descriptive, but also the evaluative and prescriptive views of the community about what counts as (what kind of) violent behaviour into account. The reason he must also take their normative views into account is that the views of the community about what counts as what kind of violent behaviour (description) are 
entangled with their normative views about what behaviour is condemnable (evaluation) and should therefore result in punishment (prescription).

Does the fact that descriptive and normative, more specifically moral, political and religious, views of the community are intertwined imply that social sciences do not describe and explain? Does it imply that social sciences are inherently evaluative in a moral, political or religious sense? The answer to both questions is 'no'. Social scientists can describe and explain changes in the number of violent acts. In doing so, it is not sufficient that they observe behaviour. They will also have to investigate, among others, whether the norms of the community have changed. This is so because an increase of violent behaviour need not be the effect of an increase of the same amount and type of aggression, but might also be caused by the fact that nowadays more types of behaviour are considered violent, condemnable and punishable within the community.

Nevertheless, this does not imply that social scientists themselves make evaluative, let alone prescriptive claims when they refer to the social norms of the members of the community they study. They do not themselves state that violent behaviour should be conceptualized in a particular way, let alone that violent behaviour is wrong and should be punished. They describe the descriptive, evaluative and prescriptive claims of the members of the community.

One might object that social scientists have to interpret the validity and the content of the social norms of the community. For this reason, or so it is argued, their descriptions are entangled with moral, political and religious evaluations after all. ${ }^{26}$ However, when social scientists interpret they (are supposed to) refer to the views of members in the community, not to their own views. In doing so, they state their own views about the views in the community. Of course, other social scientists can contest these interpretations, but so can natural scientists.

Just like natural scientific statements, the content and the truth conditions of social scientific statements are created through consensus among social scientists. What is special is that this consensus has in part as its object the consensus among members in the community about the content of their norms. This fact, however, does not stand in the way of the truth-value of social scientific statements being a matter of correspondence of these statements with reality. In this sense, social scientific statements can be just as non-normative and objective as natural scientific statements.

The fact that social facts are also value-laden does not imply that social scientific theories about law in action are normative in character. The same holds for legal doctrinal empirical theories about law in books. When legal scholars offer empirical norm-descriptions, they do not offer their own normative views about the validity and content of laws in books. On the contrary, they describe the views that legal officials declare to be the official view about the validity and the content of the positive legal order they belong to. The legal doctrinal study of law in books differs from the social scientific study of law in action in that these views mainly show from the linguistic behaviour, more in particular from the writings, of legal officials. The meaning of the linguistic behaviour of legal officials is often 
both more precise and more uniform than the meaning of the behaviour of norm subjects. For that reason the norm-descriptions that legal scholars offer of law in books can be more rather than less empirical, descriptive and objective than the descriptions social scientists offer of law in action.

\section{Non-empirical norm-descriptions}

\subsection{Law as an abstract object}

In section 2.3 I argued that law is a social object and I discussed the implications of its social character for the nature of the empirical part of legal doctrine. In this section I argue that law is not only a social object, but also an abstract object and I explicate what I mean by the terms 'social object' and 'abstract object'. Although there is no full agreement about the nature of abstract objects, most philosophers agree that abstract objects are characterized by the fact that they do not occupy a relative determinate spatial volume, that they are causally inefficacious and that they are experimentally undetectable. ${ }^{27}$ Legal orders, and elements within them, such as codes, rules, principles, values and case law are all abstract objects. Note, by the way, that not all social and legal objects are abstract objects. ${ }^{28}$ For example, whereas a banknote, which occupies a relative determinate spatial volume, is a concrete object, money, which does not exist in space, is an abstract object. Similarly we can distinguish between a concrete law book on the one hand and an abstract legal code on the other.

Some readers might worry that this talk of abstract objects leads us straight to some form of Platonism that forces us to accept the existence of ghostly non-spatiotemporal substances. For this reason most philosophers are only willing to talk about abstract ideas or concepts, but not about abstract objects as the entities that these concepts refer to. We can probably best remove their uneasiness by stressing that abstract objects are not eternal platonic forms that exist independently of human beings. Zalta (2000, p. 26-27; 2004) states that abstract objects are possible and actual patterns that are grounded in the arrangement of particles in the natural world and in the systematic behaviour, including linguistic behaviour, of mathematicians and scientists when they discover, state, and apply theories of the natural world.

In a similar vein, I argue that legal orders as abstract objects are actual and possible patterns that are grounded in the linguistic behaviour of legal officials of those

27 See Rosen 2009 and Zalta 2004. My exposition of the abstract object theory is based on Zalta's theory, especially on Zalta 1983; 2004.

28 Neither are all abstract objects social objects. For example, mathematical objects such as numbers are abstract, but they are in general not conceived of as social. This is so, because the axioms of mathematics are not, as some moral and legal rules, actively and regularly applied and enforced in the daily life of ordinary people and in that sense a matter of direct social and practical concern. 
orders. ${ }^{29}$ The distinction between actual and possible patterns is pivotal for my analysis of legal doctrine. In this section I argue that the actual patterns that are grounded in the linguistic behaviour of legal officials constitute the positive legal order as a social object, whereas some of the possible patterns constitute the positive legal order as an optimal internally coherent normative system.

The existence of a concrete object is determined by reference to its location in space-time. The fact that abstract objects have no spatial existence implies that their existence cannot be determined by reference to their location in space. The existence of an abstract object can only be determined by reference to certain properties it has. This takes us to the most important distinction between concrete and abstract objects, viz the distinction between two ways in which abstract objects can be said to have properties. ${ }^{30}$ Whereas concrete objects can only exemplify properties, abstract objects both exemplify and encode properties (Zalta 1983, p. 11-12; 2004). ${ }^{31}$ The distinction between exemplifying and encoding boils down to the question whether it is possible to empirically establish whether an object has a particular property. When this is possible, we can say that the object exemplifies the property; when this is not possible, the object encodes the property. This distinction allows us to say more both about the existence and about the identity of concrete and abstract objects.

For example, the law book on my desk is a concrete object that exemplifies the properties of having a golden colour and weighing 0,7 kilogram. It also exemplifies the property that it is being thought about by me at this moment and the property that it is in my possession. Finally, it also exemplifies the property that it contains the Dutch Code of Criminal Law. Although these physical, mental and social and legal properties are mutually very different, they are alike in that it is an empirical question whether this concrete law book really exemplifies the physical, mental, social and legal properties mentioned.

The Dutch Code of Criminal Law is an abstract object since it does not have a spatial existence. So it both exemplifies and encodes properties. For example, it exemplifies the property of having come into existence in 1881. The code also exemplifies the property of being known by its proper name by several Dutch citizens and of being though about by me at this very moment. As with concrete objects, the question whether the code really exemplifies the properties I have ascribed to it is an empirical matter, to be ascertained by empirical means.

Unlike concrete objects, abstract objects also encode properties. The properties an abstract object encodes are its defining properties, i.e. the properties in terms of

29 Ruiter 1997, p. 364 states: 'Legal individual concepts can be said to exist in a metaphorical sense insofar as the behavioural relations they purport to effectuate actually do occur. However, their mode of existence in question is that of a pattern of behaviour governed by a socially accepted fiction' (my italics, ARM). Again this suggests that a combination of abstract object theory, which offers a sophisticated explication of fictions (Zalta 2000; Yagisawa 2009), and a institutional theory of law such as Ruiter's or MacCormick's could result in an integrated theory or at least in a fruitful extension of both theories.

30 In the terminology of the abstract object theory: we should distinguish two modes of predication.

31 Zalta takes the distinction between exemplifying and encoding from Ernst Mally (1879-1944), a student of Alexius Meinong (1853-1920). 
which both the existence and the identity of the abstract object are determined (Zalta 2004). There are several types of abstract objects. Theories and stories are a specific type of abstract objects, viz objects that only encode propositions as their properties. Mathematical theories encode axioms plus their derivable propositions; stories encode propositions declared true by the author plus their 'relevant consequences'. The crucial thing to note is that the properties that an abstract object encodes cannot be determined by empirical means; they are defined by the story or theory in which they figure.

How can this talk of abstract objects help us to understand the nature of legal order, legal doctrine and in particular the nature of non-empirical norm-descriptions? First note that on the abstract object theory we can understand a legal order as a normative story and the rules, principles and values within the legal order as abstract objects within the story. We can define a legal order in the same way as Zalta defines a story. Thus, legal order $\mathrm{L}_{1}$ is that abstract object that encodes exactly those properties that are constructed out of propositions true according to the legal order, whereas legal order $\mathrm{L}_{2}$ will encode another set of properties, et cetera. ${ }^{32}$

Legal scholars, however, are interested in positive legal orders, not in just any possible legal order. How can abstract object theory distinguish between positive and possible legal orders? Here we make use of the distinction between exemplifying and encoding. First note that most modern legal orders encode the property that they are a positive legal order of a specific community (a state or a federation of states like the EU). Many legal codes explicitly encode this property since they begin with the statement that they are the code of a specific state. However, it is not sufficient for an order to be a positive order that it encodes the property that it is a positive order of a specific community or state. For an order to be a positive order there must be a community that exemplifies some of the norms that the legal order encodes as its properties in a social practice. ${ }^{33}$

How does a community exemplify norms of a legal order? It exemplifies them in the linguistic behaviour of legal officials, but it should also exemplify them, to some extent, in the non-linguistic (viz enforcing) behaviour of the legal officials and in the behaviour of the subjects of the legal order. In the former case the legal order is said to be a positive legal order, in the latter case it is an effective positive legal order. Accordingly, the linguistic behaviour of legal officials plays a double role. On the one hand the contents of the linguistic utterances of legal officials are the properties that the abstract legal order encodes, i.e. they are the properties that define the identity and the existence of the legal order as a legal order; on the other hand the fact that there are concrete legal officials that exemplify these linguistic utterances as properties is also crucial since they turn that legal order into a positive legal order.

32 In this paper I ignore the fact that legal orders, unlike stories, consist mainly of prescriptive statements, not of descriptive statements.

33 No community will perfectly exemplify a legal order. Therefore we should not demand that the community exemplifies all norms. 


\subsection{Three types of legal existence or validity}

How exactly can the linguistic behaviour of legal officials play this double role of encoding and exemplifying? In order to understand this we have to get a grasp of the fact that positive legal orders and norms they encode as properties can be said to legally exist in at least three different senses. In section 2.1 I said that law exists in the social world. It is time to explicate this claim. First note that legal orders as well as the norms and values and other objects within them have a specific mode of legal existence, viz validity.

In the first place, a legal norm with a particular content can be said to legally exist, i.e. be valid when this shows from the linguistic behaviour of legal officials, i.e. when they have declared, in their official writings, that it is valid. The first type of existence I call declarative validity. It should be emphasized that declarative validity is distinct from social validity or effectiveness, i.e. the extent to which citizens are law-abiding, i.e. the extent to which the legal norms belong to law in action.

In the second place, a legal norm can be said to be valid when legal officials have created it in accordance with the secondary or procedural rules of the positive legal order. I call it procedural validity. Note that, ideally, all declaratively valid norms are procedurally valid, but in actual practice this will not always be the case.

Third, a norm can be said to be valid when it is consistent with the substantive constraints posed by legal principles and values. Again, these principles and values are legal only when they are documented in legal sources like treaties, the constitution and case law and when they are established in accordance with the criteria of legal interpretation and argumentation acknowledged in that specific positive legal order. I will call the third type of validity substantive validity. Ideally all norms declared valid by legal officials are procedurally and substantively valid, but again in actual practice this will not always be the case. If a norm fulfils all three types of validity, I call this norm fully valid.

Procedural validity poses normative constraints on both declarative and substantive validity and substantive validity poses normative constraints on both procedural and declarative validity. However, despite these normative constraints, legal officials can declare valid norms that are not valid according to procedural or substantive standards. To return to one of the examples given in section 1.3, if regional euthanasia review committees would consider themselves authorized to judge a case of euthanasia carried out by a nurse, the norm they create would at first only be declaratively valid; only in the long run it might gain full validity.

The relevance of the distinction between these types of validity is that a complete description of law in books takes into account all three types of validity and lays bare the 'relevant consequences' of all three types of legally valid norms as well as incoherencies between them. Moreover a complete description also proposes ways to resolve the incoherencies. Since substantive and procedural validity are intra-legal constraints on the declarative validity of legal norms, statements about procedurally and substantively valid norms truly are descriptive statements about the positive legal order even if these norms are not declaratively valid. Statements about declaratively valid norms are empirical norm-descriptions of law as a social object, viz as exemplified in the linguistic behaviour of legal officials; statements 
about conflicts between and about 'relevant consequences' of declaratively, procedurally and substantively valid norms are non-empirical norm-descriptions of positive law as an optimal internally coherent normative system. As was stated in section 1.2, they are non-empirical to the extent that legal officials have not (yet) declared that they are valid.

\subsection{Authorship ${ }^{34}$ and declarative statements of legal officials}

Why is it that legal orders have several levels or types of validity? This is mainly because positive legal orders do not only exist as abstract objects, but are also exemplified by practices in which legal officials, ${ }^{35}$ by making declarative speech acts, create legal norms and other abstract legal objects. ${ }^{36}$

Mathematical theories do not have to deal with this complication because as axiomatic theories they do not have an author who can declare a statement to be true or false within the theory. Although the author of a mathematical theory can declare what are the axioms of 'his' theory, he cannot declare what follows from these axioms. What follows from 'his' axioms is independent of his convictions and intentions.

Stories, on the other hand, do have an author who can declare what is true or false in the story. Unlike both legal orders and mathematical theories, most stories have only one author who can make such declarative statements. Even though literary critics (like legal scholars) can point at inconsistencies, unclarities and gaps, it is up to the author (like legal officials) to decide whether he makes his story consistent or complete. He might do so e.g. by adapting the story in a new edition or by explaining away the inconsistency as an only apparent inconsistency. The author, however, has the authority to simply ignore the objection and leave the story as inconsistent as it is.

Legal orders are like chain-novels and soap-series in that they are characterized both by the fact that (1) they are dynamic systems, i.e. evolve, as well as by the fact that (2) they have more than one author who can make declarative statements about the validity and content of norms. That is, legal orders have many different authors, not only over time, but also at a time. Clearly, legal officials can and often will (1) declare something to be a valid norm of the legal order even though the content of this declaration conflicts with 'the logic' of the order as it is laid down in (2) procedural and/or (3) substantive norms. In other words, the declarative power of legal officials, that authorizes them to create, change and abolish substantive and procedural norms and that thereby give legal orders their dynamic character, also enables them to create norms that are incoherent with intralegal procedural or substantive norms or with both.

Finally note that whereas authors of stories are authorized to declare true propositions in their stories that conflict with other propositions in their stories, the declarative power of legal officials of a positive legal order that encodes certainty 
and equality as intra-legal values only enables but does not authorize them to declare valid norms that are inconsistent with other norms. In such a legal order coherence and completeness are either explicitly encoded as legal values or they can be derived as 'relevant consequences' from the values of certainty and equality.

\subsection{Equivalent and non-equivalent systematizations}

In section 2.2 I introduced Brouwer's concept of 'equivalent systematizations' in order to clarify the nature of the empirical part of legal doctrine. I believe that likewise his notion of 'non-equivalent systematizations' (Brouwer 1999, p. 222-224) can be helpful to further clarify the non-empirical part of legal doctrine. On my approach, an equivalent systematisation consists only of empirical norm-descriptions, whereas a non-equivalent systematisation consists of both empirical norm-descriptions as well as non-empirical norm-descriptions.

Brouwer argues that the three demands of equivalent systematizations also hold for non-equivalent systematizations. So both types of systematization should fulfil the demands of:

1. Completeness;

2. Clarity and precision;

3. Frugality.

Two extra demands hold for non-equivalent systematizations. They should offer descriptions of law:

4. As a coherent system;

5. As an optimal realisation of legal principles, values and goals.

Obviously the latter two demands do not necessarily fit harmoniously with the other demands. In the first place, these two demands do not necessarily point in the same direction as the first three demands. In section 2.2 we have seen that an equivalent account should cover, i.e. describe, all legal material, whether coherent or not. A non-equivalent account allows for a trade-off between the demand of completeness of the description and the demands of coherency and/or the optimal realisation of legal principles, values and goals. Moreover, sometimes tradeoffs between the fourth and fifth demand will be necessary too.

Since the legal order is not an axiomatic system, different trade-offs between the demands are possible. Therefore non-empirical norm-descriptions cannot always give 'one right (on my view: true) answer' ${ }^{37}$ Like many empirical norm-descriptions, they will often consist of disjunctive statements expressing several interpretations that are possible or they will offer a partial characterization of the norm. ${ }^{38}$ These non-empirical norm-descriptions show which answers are coherent and thus possible and they can also show which answers are definitively incoherent with the positive legal order. 


\subsection{Law as a semi-logical and semi-fictional abstract object}

Non-empirical norm-descriptions are claims about what legal officials would do if they were thinking rational or reasonable, i.e. normatively coherently, about positive law. Formulated yet differently, they state what the legal officials definitely could or could not declare, i.e. what they would or would not declare if they had a clear view of all of the declaratively, procedurally and substantively valid norms and values that the positive legal order encodes.

In section 1.3 I distinguished two types of non-empirical norm-descriptions: logical norm-descriptions on the one hand and semi-logical and semi-fictional normdescriptions on the other. Now it is time to explain why I call non-empirical statements that describe legal norms as formally and substantively valid semi-logical. They are similar to, but in certain respects different from, logical statements. The reason that they are not purely logical statements is that they are only partly based on logical criteria, most importantly on the demand of coherence. We have seen that they are also partly based on criteria of a different nature, viz criteria about the proper procedure and about (the hierarchy of) substantive legal principles and values as well as on criteria about (the hierarchy of) rules of interpretation and argumentation. The reason to nevertheless call these statements semilogical is that the criterion of coherence is an intra-legal criterion that plays a pivotal role in the assessment of law, especially in positive legal orders that encode equality and certainty as fundamental legal values.

In section 1.3 I have also called these non-empirical statements semi-fictional norm-descriptions. The reason to call them fictional is that they purposively attribute counterfactual properties to the positive legal order as it shows from the declaratively valid statements of legal officials. Thus, non-empirical statements treat law to some extent as a fiction or a possibility, ${ }^{39}$ viz as an object that does not exist in social reality since it is not exemplified by the practice of legal officials. By treating law as a fiction legal scholars can attribute certain counterfactual properties to positive law and likewise they can eliminate certain factual properties. However, law is not treated as a complete fiction like, for example, stories about completely fictitious or even impossible objects and events. Non-empirical norm-descriptions need to acknowledge positive legal order as it is exemplified by the practice of legal officials to an as large extent as possible, as valid law. Moreover, the kinds of changes in the legal order that the semi-fictional perspective allows for are regulated fairly precisely. For example, the non-empirical descriptive perspective does not allow for the elimination or radical re-interpretation of a too fundamental (e.g. constitutional) part of the positive legal order. Therefore, law is not treated as a fiction, but only as a semi-fiction.

39 On Zalta's account (2004) the difference between a possibility and a fiction is that fictions are highly incomplete, whereas possibilities are determinate down to the last detail. Legal orders seem to be somewhere in between fictions and possibilities. They are not determinate to the last detail, but neither are they highly incomplete. If they turn out to be highly incomplete, legal scholars cannot offer non-empirical norm-descriptions, but only contentions about these orders. 


\subsection{Conclusion}

We are now in a position to analyse the nature of the empirical and the non-empirical descriptive parts of legal doctrine. The empirical part of legal doctrine describes the content of declaratively, procedurally and substantively valid norms and it describes, but does not resolve, the incoherencies, vagueness, ambiguities and gaps between declaratively, procedurally and substantively valid norms.

The non-empirical part not merely describes the incoherencies, vagueness, ambiguities and gaps; it also offers re-interpretations of declaratively, formally and/or substantively valid norms to eliminate incoherencies, vagueness, ambiguities and gaps. In doing so it aims, by means of the criteria of coherency and the optimal realization of legal principles, values and goals that were mentioned in section 3.4, to do justice to all the properties the positive legal order encodes. However, as was stated above, since the legal order is not an axiomatic system, the non-empirical descriptive part of legal doctrine is unlikely to give 'one right (or rather true) answer'. Often it is not possible to offer more than disjunctive statements or partial characterizations.

\section{Normative statements}

\subsection{Norm-contentions}

Norm-contentions do not describe the legal order as a positive order, i.e. as an order that is exemplified by a social practice, nor do they offer a rational reconstruction of the order and describe it as an optimal internally coherent normative system. They evaluate (part of) the positive legal order by reference to extra-legal principles, values and goals that do not belong to the positive legal order itself. In formulating contentions, legal scholars offer justifications or critiques of the legal order. These contentions can but need not be based on fairly specific and coherent criteria.

These extra-legal criteria might be founded in a theory about social justice, but they might just as well relate to goals of efficiency and efficacy and be founded in a particular economic theory or in any other extra-legal values and extra-legal theory a legal scholar might find important. So again, if someone argues that the Dutch Termination of Life on Request and Assisted Suicide (Review Procedures) Bill should be abolished because it conflicts with respect for the sanctity of life, his claim would be a norm-contention because respect for the sanctity of life is not a principle of Dutch positive law.

Apart from the distinction between intra- and extra-legal criteria, the most important difference between non-empirical norm-descriptions and normcontentions is that whereas the former need to acknowledge the largest and especially the most fundamental part of the positive legal order as valid law, normcontentions need not do so. They can subject each and every part of the legal system to critique, even all of it, although, obviously, their practical relevance for and impact on the legal order will probably be greater if they respect a large part of the legal order. 


\subsection{Norm-recommendations}

Legal scholars use norm-recommendations to persuade their audience to evaluate law in the same way as they evaluate it and they can aim to persuade legal officials to accept their view as the proper one and to change the law accordingly. In section 1.3 I have made a distinction between intra-legal norm-recommendations that are based on non-empirical norm-descriptions and extra-legal norm-recommendations that are based on norm-contentions.

Intra-legal norm-recommendations differ from extra-legal norm-recommendations. In the first place, non-empirical norm-descriptions are, by definition, based on a theory about the positive legal order and thus on arguments. For this reason the recommendations are based on these arguments too. Norm-recommendations based on norm-evaluations can but need not be based on arguments.

Secondly, intra-legal norm-recommendations are like the intra-scientific theoretical and methodological recommendations scientists offer to other scientists that - if accepted - result in adaption of theoretical or methodological views. Intralegal recommendations belong to the 'proper business' of legal doctrine, whereas extra-legal recommendations are, or at least ought to be, like the contentions they are based upon, no more than sideline activities of legal scholars. Although intra-legal norm-recommendations belong to the core-business of legal doctrine, legal scholars should distinguish more clearly between the non-empirical normdescriptions that offer possible interpretations and the particular norm-recommendation that they finally choose to make.

\section{Conclusion}

Norm-contentions and the extra-legal recommendations that are based on them are normative in nature. Both legal scholars as well as scientists of other disciplines offer these kinds of evaluations and persuasions. Scientists from other disciplines present them as normative claims and separate them, in principle at least, from their descriptive and explanatory statements and their intra-scientific recommendations. Legal scholars should also separate their norm-contentions from their empirical and non-empirical norm-descriptions and present them as full-blown normative statements.

This, however, does not mean that contentions and extra-legal recommendations are subjective, i.e. non- or irrational. They are not true or false in a correspondence theoretical sense and they need not be based on criteria that are shared by legal officials or by legal scholars. However, to the extent that they are based on a coherent normative theory, they are rational statements that can be justified and criticized and that allow for improvement.

Legal scholars should distinguish contentions as extra-scientific normative claims from non-empirical norm-descriptions, in particular when they explicate the nature of legal doctrine to scientists of other disciplines. Non-empirical normdescriptions are intra-scientific claims. Laying bare the declaratively, procedurally and substantively valid norms that the positive legal order under investigation encodes as well as their 'relevant consequences' and proposing resolutions to 
their mutual incoherencies is, or at least should be, the core business of legal doctrine.

These non-empirical norm-statements truly are descriptions to the extent that they offer a description of the positive legal order. They do not offer a description of the legal order as a social object that exists in the social world through actual patterns in the linguistic behaviour of legal officials. Rather they offer a description of the positive legal order as an optimal internally coherent normative system that can only be said to exist as an abstract object, viz through the possible patterns in the linguistic behaviour of legal officials. What legal scholars do when they offer intra-legal recommendations is to argue that these patterns should become actual patterns if legal officials are to be faithful to their own, i.e. intralegal, criteria.

\section{References}

\section{Aarnio 1987}

A. Aarnio, The Rational as Reasonable, Dordrecht: Reidel 1987.

\section{Brouwer 1999}

P.W. Brouwer, 'Systematisering van recht', in: P.W. Brouwer et al. (eds.), Drie dimensies van het recht, Den Haag: Boom Juridische uitgevers 1999, p. 219-237.

\section{Leiter 2002}

B. Leiter, 'Law and objectivity', in: J. Coleman \& S. Shapiro (eds.), The Oxford Handbook of Jurisprudence and Philosophy of Law, Oxford: Oxford University Press 2002, p. 969-989.

\section{MacCormick 2007}

D.N. MacCormick, Institutions of Law. An Essay in Legal Theory, Oxford: Oxford University Press 2007.

MacCormick \& Summers 1991

D.N. MacCormick \& R.S. Summers, Interpreting Statutes, Darthmouth: Aldershot 1991.

\section{MacCormick \& Weinberger 1986}

D.N. MacCormick \& O. Weinberger, An Institutional Theory of Law, Dordrecht: Reidel 1986.

\section{Mackor 2011}

A.R. Mackor, 'Explanatory non-normative legal doctrine. Taking the distinction between theoretical and practical reason seriously', in: M. van Hoecke (ed.), Methodologies of Legal Research. Which Kind of Method for What Kind of Discipline? Oxford/Portland, Oregon: Hart Publishing 2011, p. 45-70.

\section{Mazzarese 1991}

T. Mazzarese, 'Norm-propositions: Epistemic and Semantic Queries', Rechtstheorie 1991-1, p. 39-70.

\section{Niiniluoto 1985}

I. Niiniluoto, 'Truth and Legal Norms', in: D.N. MacCormick et al. (eds.), Conditions of Validity and Cognition in Modern Legal Thought, Wiesbaden: Franz Steiner Verlag 1985, p. 168-190.

\section{Niiniluoto 1991}

I. Niiniluoto, 'Norm-propositions Defended', Ratio Juris 1991-3, p. 367-373. 


\section{Niiniluoto 2006}

I. Niiniluoto, 'World 3: A Critical Defence', in: I. Charles et al. (eds.), Karl Popper: Metaphysics and Epistemology, Farnham: Ashgate Aldershot 2006, p. 59-69.

\section{Niiniluoto 2008}

I. Niiniluoto, Facts and values - a useful distinction (paper presented at the First Nordic Pragmatic Conference, Helsinki, Finland, June 2008), <www.nordprag.org/papers/ Niiniluoto\%20-\%20Facts\%20and\%20Values.pdf>, downloaded on 9 November 2011.

\section{Peczenik 2005}

A. Peczenik, Scientia Juris, Dordrecht: Springer 2005.

\section{Putnam 2002}

H. Putnam, The Collapse of the Fact/Value Dichotomy, Cambridge MA: Harvard University Press 2002.

\section{Rosen 2009}

G. Rosen, 'Abstract Objects', in: E.N. Zalta (ed.), The Stanford Encyclopedia of Philosophy (Fall 2009 Edition), <http://plato.stanford.edu/archives/fall2009/entries/abstractobjects, last visited 9 November 2011>.

\section{Ruiter 1997}

D.W.P. Ruiter, 'A Basic Classification of Legal Institutions', Ratio Juris 1997-4, p. 357-371.

\section{Ruiter 2001}

D.W.P. Ruiter, Legal institutions, Dordrecht: Kluwer 2001.

\section{Searle 1983}

J.R. Searle, Intentionality, Cambridge: Cambridge University Press 1983.

\section{Searle 1995}

J.R. Searle, The Construction of Social Reality, London: The Penguin Press 1995.

\section{Searle 2010}

J.R. Searle, Making the Social World, Oxford: Oxford University Press 2010.

\section{Smith 2009}

C. Smith, 'Het normatieve karakter van de rechtswetenschap: recht als oordeel', Rechtsfilosofie \& Rechtstheorie 2009-3, p. 202-225.

\section{Smits 2009}

J. Smits, Omstreden rechtswetenschap, Den Haag: Boom Juridische uitgevers 2009.

\section{Soeteman 2009}

A. Soeteman, 'Wetenschappelijke rechtsgeleerdheid. Commentaar op het preadvies van Carel Smith', Rechtsfilosofie \& Rechtstheorie 2009-3, p. 226-235.

\section{Stavropoulos 2006}

N. Stavropoulos, 'Objectivity', in: M.P. Golding \& W.A. Edmundson (eds.), The Blackwell Guide to the Philosophy of Law and Legal Theory, Oxford: Blackwell Publishing 2006, p. 315-323.

\section{Yagisawa 2009}

T. Yagisawa, 'Possible Objects', in: E.N. Zalta (ed.), The Stanford Encyclopedia of Philosophy (Winter 2009 Edition), <http://plato.stanford.edu/archives/win2009/entries/possi ble-objects $>$.

\section{Zalta 1983}

E.N. Zalta, Abstract Objects, Dordrecht: Reidel 1983.

\section{Zalta 1992}

E.N. Zalta, 'On Mally's Alleged Heresy: A Reply', History and Philosophy of Logic 1992-1, p. 59-68. References to pagenumbers are to the version of the paper on <http:// mally.stanford.edu/Papers/jacquette.pdf, last visited 28 October 2011>. 


\section{Zalta 2000}

E.N. Zalta, 'The Road Between Pretense Theory and Abstract Object Theory', in: A. Everett \& T. Hofweber (eds.), Empty Names, Fiction and the Puzzles of Non-Existence, Stanford: CSLI Publications 2000, p. 117-147. References to pagenumbers are to the version of the paper on $\langle$ http://mally.stanford.edu/Papers/pretense.pdf $\rangle$, last visited 26 August 2011.

\section{Zalta 2004}

E.N. Zalta, 'The Theory of Abstract Objects', Metaphysics Research Lab 2004, <http:// mally.stanford.edu/theory.html>, last visited 9 November 2011. 